\title{
A interoperabilidade semântica entre acervos de museus: discutindo o caso dos Museus da Imagem e do Som
}

\author{
Renata Cardozo Padilha \\ Doutoranda; Universidade Federal de Santa Catarina, Florianópolis, SC, Brasil; \\ renatapadilha@hotmail.com \\ Lígia Maria Arruda Café \\ Doutora; Universidade Federal de Santa Catarina, Florianópolis, SC, Brasil; \\ ligia.cafe@ufsc.br
}

Resumo: A interoperabilidade entre sistemas de informação pressupõe o emprego de padrões e protocolos que viabilizem a comunicação de dados entre as instituições museológicas. É neste contexto que o presente artigo procura conhecer como museus de mesma tipologia descrevem a informação contida em seus acervos e como dialogam entre si. Para tanto, escolheu-se investigar a descrição de fotografias históricas em Museus da Imagem e do Som por meio da análise dos metadados registrados em suas fichas de catalogação. Os resultados encontrados revelam a presença de um conjunto reduzido de metadados comuns às instituições pesquisadas, além de ambiguidades denominativas e conceituais que prejudicam o compartilhamento e a recuperação da informação entre as instituições examinadas e o acesso à informação pelo usuário. Conclui-se que há necessidade de se pensar caminhos para gerir e documentar os acervos dos museus na perspectiva da interoperabilidade, ampliando, assim, as potencialidades de preservação da informação e de produção do conhecimento.

Palavras-chave: Interoperabilidade semântica. Acervo fotográfico histórico. Documentação museológica. Museu da imagem e do som. Análise documentária de fotografias.

\section{Introdução}

O presente artigo discute questões de natureza terminológica que envolvem a interoperabilidade semântica no processo de compartilhamento de informações entre acervos de diferentes instituições. Essa temática é o pano de fundo da pesquisa de dissertação concluída, de título O Museu como espaço de pesquisa: proposta para descrição do acervo fotográfico histórico (PADILHA, 2014), que procurou analisar a fotografia histórica como documento, fonte de pesquisa e 
suas formas de descrição no contexto dos museus (PADILHA; CAFÉ, 2014), com o intuito de facilitar o acesso à informação pelo pesquisador.

Ao compreendermos que a falta de uma padronização terminológica na criação dos metadados pode prejudicar a interoperabilidade semântica dos sistemas de informação (ANDRADE; CERVANTES, 2012) e, consequentemente, dificultar o diálogo entre as instituições, discutimos sobre as denominações dos metadados adotadas para descrever os objetos museológicos salvaguardados nos museus.

Tendo em vista a impossibilidade de abarcar todo universo de museus e acervos, foi necessário estabelecer um recorte e, assim, obter um conjunto de dados cujo tratamento resultasse em um exame mais aprofundado do fenômeno estudado. Para tanto, escolheram-se os museus cujo acervo é constituído da temática imagem e som, e focamos em um tipo de objeto museológico: a fotografia histórica ${ }^{1}$, considerando a perspectiva do pesquisador.

Utilizamos como fonte de coleta de dados, as fichas de catalogação dos museus selecionados. Levando-se em conta a importância econômico-geográfica do Sul e Sudeste brasileiros, elegemos especificamente os Museus da Imagem e do Som situados nestas regiões.

Neste contexto investigativo, seguimos norteados pela seguinte questão de pesquisa: considerando a importância da precisão e clareza das denominações e significados para o entendimento dos metadados, na perspectiva da interoperabilidade semântica entre sistemas de informação, pergunta-se em que estado se encontra a descrição da fotografia histórica nos Museus da Imagem e do Som situados nas regiões Sul e Sudeste do Brasil? Estará esta descrição contribuindo para a comunicação entre os sistemas de informação das instituições examinadas e, em última instância, para a eficiência da recuperação da informação?

A abordagem deste artigo se baseia na relação da Museologia com a Ciência da Informação (ARAÚJO, 2014; BARBUY, 2008), tendo como foco o processo da documentação museológica pela perspectiva da Organização da Informação (OI). É considerado, nesse caso, que os estudos do campo da OI podem preencher lacunas ainda sem solução no funcionamento dos sistemas de informação e documentação dos museus, já que "Desde sua origem os museus 
viram-se às voltas com tarefas relacionadas à representação de seus acervos.". (ARAÚJO, 2014, p. 80).

\section{O sistema de documentação museológica: outro olhar para a descrição dos objetos museológicos}

A organização da informação é um processo que tem por intuito descrever o objeto informacional, revelando suas características com base em critérios e parâmetros definidos, o que resulta na representação da informação também denominada informação documentária ${ }^{2}$.

Brascher e Café $(2008$, p. 5) afirmam que o produto da representação da informação pode ser entendido "[...] como um conjunto de elementos descritivos que representam os atributos de um objeto informacional específico [...]", sendo este produto fundamental para a recuperação da informação. Nesse contexto, cabe ressaltar que a organização da informação:

[...] compreende, também, a organização de um conjunto de objetos informacionais para arranjá-los sistematicamente em coleções, neste caso, temos a organização da informação em bibliotecas, museus, arquivos [...]. (BRÄSCHER; CAFÉ, 2008, p. 6).

A informação documentária, resultante da organização da informação, é registrada em metadados, esses que se referem a "Cada um dos elementos de informação que são usados para descrever e gerir dados significativos de um sistema de informação em Internet.” (BARITÉ, 2015, p. 104, tradução nossa ${ }^{3}$ ). Conforme Campos, Campos e Campos (2006, p. 60), metadados têm por objetivo "[...] documentar, com elementos descritores, qualquer tipo de recurso disponível na Web, para permitir comunicabilidade e interoperabilidade entre sistemas.". Por metadados se compreende os dados que fazem referência a outros dados, ou seja, trata-se de elementos que permitem a descrição de forma e conteúdo das informações de um objeto/documento (MARCONDES, 2006).

Conforme Moura (2011, p. 167), o conceito de interoperabilidade diz respeito à "[...] capacidade de sistemas autônomos (informatizados ou não) [se] comunicarem de modo transparente entre si, devido à adoção de padrões comuns e protocolos que permitem o uso compartilhado de informações.". De acordo com o Diccionario de organización del conocimiento: Clasificación, Indización, Terminología, a interoperabilidade é a: 


\author{
A interoperabilidade semântica entre acervos de \\ museus: discutindo o caso dos Museus da Imagem e do \\ Som
}

Renata Cardozo Padilha, Lígia Maria Arruda Café

Capacidade intrínseca de dois ou mais sistemas de organização do conhecimento ou sistemas de informação, para compartilhar, trocar e pesquisar dados ou informações. A norma ANSI/NISO 2010 [...] identifica sete fatores que afetam a interoperabilidade: a) a similaridade entre os conteúdos temáticos em diferentes domínios; b) os vocabulários controlados diferentes usados para índice conteúdo de domínios semelhantes; c) a especificidade gradual ou granularidade dos vocabulários controlados usados para índice diferentes conteúdos de domínios ou bases de dados; d) as diferenças no tratamento de sinónimos e quase sinónimos; e) as metodologias de pesquisa exigidas pelas bases de dados usados; f) as garantias literárias, de usuário e organizacional usados no desenvolvimento de vocabulário; g) os fins previstos pelos responsáveis de bases de dados e sistemas. (BARITÉ, 2015, p.8990, tradução nossa ${ }^{4}$ ).

A interoperabilidade se apresenta em vários níveis de complexidade e “[...] toma como referência o estabelecimento da representação estrutural, sintática, semântica e lógica." (MOURA, 2011, p. 167). No caso desta investigação, interessam-nos as questões relativas à interoperabilidade semântica, que, de acordo com Moura, situa-se no segundo nível de complexidade e se define:

[...] pela interconectividade e a garantia sistêmica de que as informações compartilhadas entre diferentes sistemas e aplicações poderão ter seus significados compreendidos e operacionalizados em distintas etapas do desenvolvimento de um projeto. Para garantir a compatibilidade dos dados e dos procedimentos adotados é necessário o compartilhamento de convenções e protocolos de comunicação e um sistema conceitual subjacente às diferentes aplicações. (MOURA, 2011, p. 168).

Andrade e Cervantes apontam que:

A interoperabilidade semântica está relacionada não só com a forma com que o dado pode ser entendido por humanos e por programas de computador, mas com a diversidade de idioma; a sintática (diferenças na codificação e na representação da informação) e os esquemas de metadados. Entende-se que os elementos de metadados representam as propriedades dos recursos, e que recurso é o objeto/item e pode conter descrições mais específicas atribuídas por meio de qualificadores que adicionam valores. (ANDRADE; CERVANTES, 2012, p. 157).

Sendo assim, conclui-se que a falta de uma padronização terminológica dos metadados pode prejudicar a interoperabilidade semântica entre sistemas de informação (ANDRADRE; CERVANTES, 2012).

A ideia apresentada acima é refletida, neste estudo, no âmbito das práticas das instituições museológicas, mais especificamente no que diz respeito 
ao processo de documentação museológica dos objetos salvaguardados em museus. Além disso, o cenário discutido nos leva a olhar os objetos museológicos por outra perspectiva: não somente como bem cultural, mas também como fonte de informação para a pesquisa científica.

A documentação museológica é estruturada por duas perspectivas: a documentação das práticas administrativas e a documentação dos objetos museológicos. Para a presente discussão, cabe a análise do processo de documentação dos objetos, que vai da seleção até a disponibilização dos mesmos ao público. As etapas que permeiam este processo são estabelecidas por meio de pesquisa, interpretação, organização, armazenamento e disseminação da informação contida nos objetos museológicos salvaguardados em acervos de museus.

Conforme expõe Holm,

A documentação de coleções é toda a informação registrada que um museu possui sobre os bens que protege, também inclui a recolha, armazenamento, manipulação e recuperação das informações. Ele não é um fim em si mesmo. É o meio pelo qual tanto o pessoal do museu e os visitantes podem encontrar as informações de que necessitam. Permite uma adequada gestão compulsão e interpretacão das coleções do museu, agora e no futuro. (HOLM, 1991 apud CARRETERO PÉREZ et al., 1998, p .1, tradução nossa ${ }^{5}$.

Segundo o autor, a documentação museológica não é o fim, mas o meio que viabiliza as atividades relacionadas ao museu. A documentação facilita o funcionamento da instituição tendo em vista a segurança do acervo, a dinâmica de trabalho dos funcionários, o reconhecimento das coleções salvaguardas pelo museu, a gestão do acervo e da instituição, bem como a preservação física e informacional dos objetos, seja de caráter próprio ou administrativo, como também promove o acesso à pesquisa científica (FERREZ, 1994; SMIT, 2011).

Tendo em vista que o foco deste artigo é o processo de documentação dos objetos, compreendemos como objeto museológico aquele que, por meio da investigação das características intrínsecas e extrínsecas (FERREZ, 1994), passa por um processo de ressignificação de suas funções e sentidos. Assim, compreende-se que qualquer objeto possui potencial para ser um objeto museológico; no entanto, o que o legitimará nessa categoria é a análise que a 
instituição fará no momento em que este for adquirido (PADILHA, 2014). Evidencia-se a necessidade de que o objeto adquirido possua afinidade com o tipo de acervo salvaguardado pelo museu, bem como apresente ligação com a missão e os objetivos da instituição.

Observa-se que os objetos, ao longo de sua existência, perdem e ganham informações em consequência de sua funcionalidade, reparos e deterioração. Quando adentra a instituição museológica, inicia uma nova história que deverá continuar sendo documentada. Por isso, Ferrez (1994, p. 67) afirma que:

Nos museus ele também ganha informação através, sobretudo, de pesquisas e da sua reutilização (ex. exposições), e perde informação quando, por exemplo, é restaurado ou privado de sua função original.

Por isso, ao pensar no objeto museológico, deve-se levar em conta a informação que este carrega consigo antes e depois de ser adquirido pelo museu. Além disso, é necessário considerar que todas as práticas pelas quais passam os objetos museológicos no decorrer da sua permanência na instituição necessitam ser registradas para que a circulação da informação e a segurança do acervo sejam legitimadas.

Diante do exposto, o objeto museológico, compreendido como bem cultural, também é visto como fonte de informação para a pesquisa científica e que, para tanto, necessita ter suas possibilidades de informação ampliadas com vistas a explorar a produção de conhecimento por meio dele. Com base no que aborda Ferrez (1994), cabe ao processo de documentação dos objetos museológicos transformá-los de fontes de informação em fontes de pesquisa científica, uma vez que sua organização visa facilitar o acesso e a recuperação da informação, com o intuito de auxiliar na produção do conhecimento.

Nesse contexto, é responsabilidade daqueles que gerenciam o sistema de documentação museológica viabilizar a comunicação efetiva entre as fontes de informação, mais especificamente entre os objetos museológicos e o usuário/público. Barbuy (2008, p. 37) afirma que os sistemas de documentação têm por objetivo principal: 
externas, e se alimente, por sua vez, das pesquisas realizadas sobre o acervo institucional ou em torno dele.

O intuito desse sistema é conservar os objetos da coleção, potencializar o acesso e elevar ao máximo o uso da informação neles contida.

Cabe ressaltar que a documentação precisa dar conta dessas informações intrínsecas e extrínsecas ao objeto museológico, por isso a clareza e exatidão dos dados, a definição dos campos de informação, a normalização de procedimentos, o controle terminológico e a segurança da documentação, entre outros, devem ser atentamente desenvolvidos (FERREZ, 1994).

No que diz respeito à descrição dos objetos, identificamos a ficha de catalogação como um importante recurso para a documentação museológica. Bottallo (2010, p. 63) afirma que a ficha “[...] não é um documento, mas uma ferramenta de trabalho que reúne uma série de informações que, de outra forma, estariam dispersas.". Diante disso, verificamos que a normalização dos descritores bem como o controle terminológico se tornam primordiais. Segundo a autora, a documentação museológica deve ser padronizada, e

Para que isso seja claro para todos os envolvidos no processo de catalogação, será muito importante criar - sistematicamente rever manuais de procedimentos de catalogação com regras para a utilização e preenchimento de cada campo da ficha catalográfica e/ou do banco de dados sobre o acervo. (BOTTALLO, 2010, p. 54).

Preocupados com esta questão, busca-se relatar neste estudo a situação da descrição da fotografia histórica como documento representado nas fichas de catalogação dos Museus da Imagem e do Som, das regiões Sul e Sudeste do Brasil, procurando observar como estas instituições estão pensando o compartilhamento de informações e a comunicação entre seus acervos.

\section{Procedimentos metodológicos}

Realizou-se um levantamento documental das fichas de catalogação dos Museus de Imagem e do Som referente aos acervos fotográficos salvaguardados nos museus brasileiros. O propósito foi identificar quais são os metadados utilizados pelos museus para descrever fotografias históricas.

Para a seleção dos museus examinados, adotaram-se como critérios a instituição apresentar em seu nome a expressão exata "Museu da Imagem e do 
Som" e estarem situadas em capitais nas regiões Sul e Sudeste ${ }^{6}$. No que se refere à denominação, justifica-se por compreendermos que a missão e os objetivos dos museus assim nomeados teriam maior proximidade em suas atividades estruturais e, consequentemente, teriam maior probabilidade de seu acervo fotográfico estar descrito em fichas de catalogação.

O critério regional deve-se pela proximidade geográfica do local onde a pesquisa foi realizada e por considerar que nas capitais é possível que se encontre um acervo que represente de forma mais ampla e completa a história, a sociedade, a cultura e a arte de uma determinada região. A aplicação deste parâmetro resultou em quatro instituições: Museu da Imagem e do Som (São Paulo - SP), Fundação Museu da Imagem e do Som do Rio de Janeiro (Rio de Janeiro - RJ), Museu da Imagem e do Som do Paraná (Curitiba - PR) e Museu da Imagem e do Som de Santa Catarina (Florianópolis - SC).

Uma vez selecionadas as instituições, foi solicitada a ficha de catalogação que descrevem seus acervos fotográficos. Como o intuito era verificar o nível de compartilhamento de dados entre estes museus, passou-se então a realizar o cruzamento de suas fichas e a identificar o cenário que se apresentava no que dizia respeito ao significado e denominação dos metadados.

Seguem abaixo os critérios determinados para análise dos metadados adotados nas fichas de catalogação dos Museus de Imagem e do Som:

a) identificar os metadados de cada ficha de catalogação dos Museus;

b) averiguar a ocorrência dos metadados nas fichas dos Museus selecionados;

c) verificar a denominação dos metadados a fim de identificar possíveis ambiguidades.

\section{O caso dos Museus da Imagem e do Som: sobre a interoperabilidade semântica nas fichas de catalogação para acervo fotográfico histórico}

Do ponto de vista quantitativo, cada ficha de catalogação analisada contém: 41 (SP), 19 (RJ), 37 (PR) e 20 (SC) metadados, o que totaliza 117 metadados. A comparação entre eles nos levou a constatar que 43 metadados (36,7\%) pertencem exclusivamente a uma única ficha de catalogação. Destes, 18 tratam de assuntos gerais que poderiam estar presentes em todas as fichas: objetos 
associados, histórico, bibliografia, referência bibliográfica, legibilidade, legendas, data de impressão, gênero, descritores onomásticos, descritores geográficos, formato, cromia, assinado, transcrição de assinatura, notação, documento de incorporação, fontes de pesquisa e posição do álbum/série.

Destacamos, a título de exemplo, o metadado objetos associados, campo que, por ter a função de agregar dados, deveria estar presente em todas as fichas. A ele podem ser vinculados outros objetos que se relacionam com a fotografia, como a câmera do fotógrafo e partes dos equipamentos do estúdio, entre outros. Além disso, foi identificado que seis dos 43 metadados presentes em uma única ficha estão ligados diretamente à instituição, mais especificamente a forma de organização do acervo: por exemplo, o metadado setor, que se refere à divisão em que está localizado o objeto no acervo. Neste caso, depende de como o museu gera e organiza seu acervo e como denomina as partes que compõem sua estrutura institucional.

Em uma das fichas notamos metadados individuais muito subjetivos e que aparentemente não atendem especificamente à organização de fotografia histórica. O Museu do Paraná apresenta uma ficha geral e outra específica, sendo que a geral busca atender a outros tipos de acervos que não só o fotográfico. Constatamos que o fato desta ficha geral não apresentar definições dos metadados dificulta a compreensão de quais desses se referem à representação da fotografia histórica. Essa imprecisão pode ser observada nos metadados: título/direção, material, velocidade, bitola, imagem, som, combinado, sistema, tela, janela, montado, completo, separado e versão. Este caso diz respeito ao grande espectro de significados possíveis para designar o metadado (veja, por exemplo, o metadado combinado). O que se percebe, neste caso, é que a falta de uma definição clara e objetiva sobre do que se trata o metadado permite uma ampla possibilidade de interpretações, prejudicando a descrição do acervo, assim como a recuperação do objeto pelo público/pesquisador.

Em outra perspectiva, verificamos também quais metadados eram comuns às fichas de catalogação analisadas. Esse é outro caminho que nos ajuda a compreender um pouco mais a respeito do que, de fato, está sendo aplicado 
nos museus brasileiros de mesma tipologia (imagem e som) na linha da interoperabilidade.

Levando em conta que um dos principais requisitos para alcançar a interoperabilidade entre diferentes instituições museológicas - e assim melhorar a recuperação - é que as bases de dados tenham um conjunto mínimo de campos comuns, levantamos quais metadados estariam presentes em todas as fichas. $\mathrm{O}$ resultado, apresentado no Quadro 1, mostra um grupo de oito metadados que, a nosso ver, não é representativo para a descrição do objeto museológico como almejado nesta pesquisa. Esta quantidade nos parece bastante reduzida e prejudicial à interoperabilidade quando consideramos os totais de metadados por ficha - 41, 19, 37 e 20 - apresentados acima. Observa-se ainda que estes oito metadados não são designados pelo mesmo termo em cada ficha, o que pode incorrer em ambiguidades e problemas de entendimento do conteúdo que se deseja representar ou recuperar. A análise do Quadro 1 nos permite verificar os diferentes termos utilizados nas fichas para designar o mesmo metadado.

Quadro 1 - Conjunto de metadados comuns nas fichas de catalogação dos museus

\begin{tabular}{|c|}
\hline Metadados \\
\hline Nome do objeto/Título \\
\hline $\mathrm{N}^{0}$ de Inventário/ $\mathrm{N}^{0}$ de entrada/No de registro/Código \\
\hline Outros números/ Código do material/Número de Ordem - ID e Número de Patrimônio - Pl/Patrimônio \\
\hline Suporte/Tipo de material \\
\hline Autor/Autoridades/Nome do autor e função \\
\hline Estado de conservação/Conservação \\
\hline Observações/Notas \\
\hline Ano de produção/Data \\
\hline
\end{tabular}

Fonte: Dados da pesquisa.

Este cenário nos preocupa em dois aspectos principais. Primeiramente, pergunta-se: em que medida os museus estão cientes dos benefícios de interagir com instituições de mesma tipologia de acervo? Em seguida, indaga-se se estas instituições conhecem o alcance da interoperabilidade no atendimento às necessidades informacionais do público/pesquisador de acervo de museus. Em outras palavras, como os museus selecionados estão pensando a interoperabilidade semântica como meio para alcançar o intercâmbio, a disponibilização e o acesso à informação pelo público/pesquisador? 
Conforme já ressaltado, a interoperabilidade realiza-se em diversos níveis; entre eles está o semântico, que inclui a denominação clara e precisa dos metadados para aprimoramento dos processos de busca e localização do documento.

A observação dos termos descritos na segunda linha do Quadro1 ( $\mathbf{n}^{\mathbf{0}}$ do inventário, $\mathbf{n}^{\mathbf{0}}$ de entrada, $\mathbf{n}^{\mathbf{0}}$ de registro e código), por exemplo, permite-nos perceber que todos os metadados descrevem a mesma informação, porém se utilizam de terminologia variada. Esta variação denominativa prejudica a troca de informação relativa a dados administrativos no nível institucional entre os quatro museus, além de dificultar a recuperação pelo usuário (pesquisador ou público em geral) ${ }^{7}$. Verificamos que o mesmo caso também ocorre com os metadados registrados na quinta linha do Quadro 1: autor (Museus da Imagem e do Som de Santa Catarina e Paraná), autoridades (Museu da Imagem e do Som de São Paulo) e nome do autor e função (Fundação Museu da Imagem e do Som do Rio de Janeiro), bem como os metadados referentes a outros números de registro estabelecidos pelas instituições, como (terceira linha da Quadro 1): outros números (Museu da Imagem e do Som de Santa Catarina), código do material (Museu da Imagem e do Som do Paraná), número de ordem - ID e número de Patrimônio - PI (Museu da Imagem e do Som de São Paulo) e patrimônio (Fundação Museu da Imagem e do Som do Rio de Janeiro).

Outro ponto a ser evidenciado trata dos metadados com ambiguidade denominativa, encontrados nas fichas de catalogação, como: bibliografia, referência bibliográfica ${ }^{8}$, código do material, combinado, sistema, tela, janela, montado, completo, separado, versão, diálogos, metadados, assinado, notações e fontes de pesquisa. Percebemos que, por não haver uma definição para cada metadado, a compreensão dos mesmos possibilita múltiplas interpretações. Segundo Cintra (2002, p. 70):

A ambiguidade, por sua vez, é entendida como a possibilidade de uma comunicação linguística prestar-se (sic) a mais de uma interpretação e ocorre em função, (sic) tanto da plurissignificação como da polissemia.

Felizmente, constatamos, no exame das fichas, metadados com a mesma denominação; no entanto não se repetem sempre em todos os museus 
analisados. Estes são mostrados no Quadro 2 acrescidos dos museus que os utilizam.

Quadro 2 - Metadados com a mesma Nomenclatura nas fichas

\begin{tabular}{|l|l|}
\hline METADADOS & MUSEUS DA IMAGEM E DO SOM \\
\hline Título & PR, SP, RJ \\
\hline Modo de aquisição & SC, PR \\
\hline Suporte & SC, PR, SP, RJ \\
\hline Procedência & SC, PR, SP \\
\hline Origem & SC, PR \\
\hline Autor & SC, PR \\
\hline Descrição & SP, RJ \\
\hline Data & PR, SP, RJ \\
\hline Estado de conservação & SC, SP, RJ \\
\hline Dimensões & SP, RJ \\
\hline Observações & SC, PR, SP \\
\hline Descritores & PR, SP \\
\hline Local & PR, SP, RJ \\
\hline
\end{tabular}

Fonte: Dados da pesquisa.

De forma geral, percebemos que a preocupação dos museus em dialogar, pelo menos, com as instituições semelhantes a eles ainda é incipiente. Além disso, identificamos que, se os museus mantivessem um grupo representativo de metadados comum a todos e adotassem a mesma terminologia registrada de forma não ambígua, estariam no caminho para alcançar a interoperabilidade semântica e facilitariam o acesso à informação pelo pesquisador, como também pelo público em geral e até mesmo para os próprios funcionários.

\section{Considerações finais}

Os dados levantados na presente pesquisa impulsionam, em primeira instância, a reflexão sobre as questões de interoperabilidade semântica e os pontos de acesso necessários à recuperação do objeto museológico. Ao observarmos quais metadados são recorrentes nas fichas e quais são individuais ou pouco utilizados pelos museus, identificamos imediatamente que os metadados, em muitos casos, possuem terminologias distintas para se referir ao mesmo conceito ou são designados por termos cujo significado muito geral pode induzir à ambiguidade, o que exige um esforço do público/pesquisador em reconhecer suas correspondências. 
Diante do exposto, buscamos refletir brevemente sobre de que forma a interoperabilidade entre sistemas de documentação de museus está presente nas práticas das instituições e como pode contribuir no acesso, na organização, na gestão e na comunicação dos acervos. Percebe-se que, ao construir caminhos para gerir e documentar os acervos de diferentes museus, pela perspectiva da interoperabilidade, podemos ampliar as potencialidades de pesquisa, comunicação e preservação destes, bem como contribuir para a produção de conhecimento.

Verificamos que a interoperabilidade semântica é uma característica importante para pensar os sistemas de informação dos acervos de museus, uma vez que visa ao compartilhamento de informação e, com isso, contribui e amplia a produção do conhecimento. Consideramos, neste caso, que tanto os museus quanto o público/pesquisador ganhariam com essa perspectiva, tendo em vista que a comunicação entre os museus e desses com o seu público se expandiria e fomentaria outros tantos meios de interação social e cultural.

\section{Referências}

ANDRADE, M. C.; CERVANTES, B. M. N. A contribuição da organização do conhecimento para a interoperabilidade: alternativas para repositórios institucionais. Informação @ Profissões, Londrina, v. 1, n. 1/2, p. 152-170, jun./dez. 2012. Disponível em:

$<$ http://www.uel.br/revistas/uel/index.php/infoprof/article/view/14593>. Acesso em: 23 set. 2013.

ARAÚJO, C. A. A. Arquivologia, Biblioteconomia, Museologia e Ciência da Informação: o diálogo possível. Brasília: Briquet de Lemos, 2014.

BARBUY, H. Documentação museológica e pesquisa em museus. In: MUSEU DE ASTRONOMIA E CIÊNCIAS AFINS (MAST). Documentação em Museus. Rio de Janeiro: MAST, 2008. p. 33-43. (MAST Colloquia, v. 10). Disponível em: $<$ http://www.mast.br/livros/mast_colloquia_10.pdf $>$. Acesso em: 19 ago. 2016.

BARITÉ, M. Diccionario de Organización del Conocimiento: clasificación, Indización, Terminología. 6. ed. Montevideo: CSIC, 2015.212p.

BOTTALLO, M. Diretrizes em documentação museológica. In: ASSOCIAÇÃO CULTURAL DE AMIGOS DO MUSEU CASA DE PORTINARI.

Documentação e conservação de acervos museológicos: diretrizes. 
Brodowski: Associação Cultural de Amigos do Museu Casa de Portinari; São Paulo: Secretaria de Estado da Cultura de São Paulo, 2010. p. 48-79.

BRASCHER, M.; CAFÉ, L. Organização da informação ou organização do conhecimento. In: ENCONTRO NACIONAL DE PESQUISA EM CIÊNCIA DA INFORMAÇÃO, 9., 2008, São Paulo. Anais... São Paulo: USP, 2008. p. 114.

CAMPOS, M. L. C; CAMPOS, M. L. A.; CAMPOS, L. M. Web semântica e a gestão de conteúdos informacionais. In. MARCONDES, C. H. et al. Bibliotecas digitais: saberes e práticas. Salvador: UFBA; Brasília: IBICT, 2006. p. 55-73.

CINTRA, A. M. M. et al. Para entender as linguagens documentárias. 2. ed. São Paulo: Polis, 2002. 92p. (Coleção Palavra-chave).

CARRETERO PÉREZ, A. et al. Normalización documental de museos: elementos para una aplicación informática de gestión museográfica. Madrid: Ministerio de Educación y Cultura, 1998. Disponível em:

$<$ http://www.mecd.gob.es/cultura-mecd/areascultura/museos/mc/ndm/capitulos.html >. Acesso em: 19 ago. 2016.

FERREZ, H. D. Documentação museológica: teoria para uma boa prática. In: CADERNOS de ensaios, $\mathbf{n}^{\mathbf{0}}$ 2. Rio de Janeiro: Minc/Iphan, 1994. p. 64-73.

LEITE, M. M. Retratos de família: leitura da fotografia histórica. 3. ed. São Paulo: EdUSP, 2001.

MARCONDES, C. H. Metadados: descrição e recuperação de informações na Web. In: MARCONDES, C. H. et al. (Orgs.). Bibliotecas digitais: saberes e práticas. 2. ed. Salvador: EDUFBA; Brasília: IBICT, 2006. p. 95-111.

MOURA, M. A. Interoperabilidade semântica e ontologia semiótica: a construção e o compartilhamento de conceitos científicos em ambientes colaborativos online. Informação \& Informação, Londrina, v. 16, n. 3, p. 165 179, jan./jun. 2011. Disponível em:

<http://www.uel.br/revistas/uel/index.php/informacao/article/view/10392/0>.

Acesso em: 18 out. 2013.

ORTEGA, C. D. Fundamentos da organização da informação frente à produção de documentos. Transinformação, Campinas, v. 20, n. 1, p. 7-15, jan./abr.

2008. Disponível em: $<$ http://periodicos.puccampinas.edu.br/seer/index.php/transinfo/article/view/537>. Acesso em: 14 ago. 2012.

PADILHA, R. C. O museu como espaço de pesquisa: proposta para descrição do acervo fotográfico histórico. 2014. 135 f. Dissertação (Mestrado em Ciência da Informação) - Programa de Pós-Graduação em Ciência da Informação, Universidade Federal de Santa Catarina, Florianópolis, 2014. Disponível em: 
$<$ https://repositorio.ufsc.br/bitstream/handle/123456789/123241/325935.pdf?seq uence $=1 \&$ is Allowed=y>. Acesso em: 19 ago. 2016.

PADILHA, R. C.; CAFE, L. M. A. Organização de acervo fotográfico histórico: proposta de descrição. InCID: Revista de Ciência da Informação e

Documentação, Ribeirão Preto, v. 5, n. 1, p. 90-111, mar./ago. 2014.

Disponível em: <http://www.revistas.usp.br/incid/article/view/73527/82240>. Acesso em: 19 ago. 2016.

SMIT, J. W. A interoperabilidade semântica entre os diferentes sistemas de informação no museu. In: SEMINÁRIO SERVIÇOS DE INFORMAÇÃO EM MUSEUS, 1., 2011, São Paulo. Anais... São Paulo: Pinacoteca do Estado, 2011. p. 33-41. Disponível em:

$<$ http://biblioteca.pinacoteca.org.br:9090/publicacoes/index.php/sim/article/view /8/7>. Acesso em: 19 ago. 2016.

\title{
Semantic interoperability among museum collections: the case for image and sound museums
}

\begin{abstract}
Interoperability among information systems presupposes using standards and protocols that facilitate data exchange among museums. From this stance, this article aims to look at how similar museums describe information in their archives and how they communicate with each other. Descriptions of historical photographs in image and sound museums were analysed using metadata from their catalogues, and results have shown that there is only a limited amount of metadata shared among these institutions. Research has also highlighted denominative and conceptual ambiguities that hinder both information sharing and retrieval among said institutions, as well as user access to information. The paper concludes that there is a need for interoperable forms of managing and documenting museum collections, which will then increase ability to preserve and perpetuate human knowledge.
\end{abstract}

Keywords: Semantic interoperability. Photography archives. Museum documentation. Museum of Sound and Image. Documentary analysis of photographs

Recebido: 02/05/2016

Aceito: $24 / 07 / 2016$

\footnotetext{
${ }^{1}$ Compreendemos como fotografia histórica "[...] toda aquela que nos chega às mãos pronta, tendo sido produzida há algum tempo, com relação ao momento em que é analisada pelo observador [...]" (LEITE, 2001, p. 15) e que, por meio de seu suporte físico e seu conteúdo
} 
imagético, possibilita investigar o contexto histórico, social, cultural, econômico e artístico relacionado a um determinado espaço-tempo.

${ }^{2}$ Segundo Ortega, o conceito de informações documentárias é definida como "unidades de representação, construídas sob uma forma e um conteúdo, a partir de decisões pautadas nos tipos de informação nas áreas do conhecimento ou de atividade, na linguagem dos usuários e nos objetivos do serviço de informação, tornando explícito o propósito de um sistema de informação.” (ORTEGA, 2008, p. 2).

3 "Cada uno de los elementos de información que son utilizados para describir y gestionar datos significativos de un recurso de información em internet.” (BARITÉ, 2015, p. 104).

4 "Capacidad intrínseca de dos o más sistemas de organización del conocimiento o sistemas de información, para compartir, intercambiar y buscar datos o información. La norma ANSI/NISO 2010 [...] identifica siete factores que afectan la interoperabilidad: a) la similaridade entre contenidos temáticos em los diferentes domínios; b) los vocabulários controlados diferentes usados para indizar contenido de domínios similares; c) la especificidad gradual o granularidad de los vocabulários controlados usados para indizar diferentes contenidos de domínios o bases de datos; d) las diferencias en el tratamento de sinónimos y cuasi sinónimos; e) las metodologias de búsqueda requeridas por las bases de datos utilizadas; f) las garantias literária, de usuário y organizacional usadas em el desarrollo del vocabulário; g) los propósitos pretendidos por los responsables de bases de datos y sistemas." (BARITÉ, 2015, p. 89-90).

${ }^{5}$ HOLM, S.A. Facts and artifacts: how to document a museum collection. Cambridge: Museum Documentation Association, 1991.

"La documentación de colecciones es toda la información registrada que un museo posee respecto a los bienes que custodia tambien contempla la actividad de recogida, almacenamiento, manipulación y recuperación de esa información. No es un fin en sí mismo. Es el medio a través del cual tanto el personal de museo como los visitantes pueden encontrar la información que necesitan. Permite una adecuada gestión compulsión e interpretación de las colecciones del museo, ahora y en el futuro." (HOLM, 1991 apud CARRETERO PÉREZ et al., 1998, p.1).

${ }^{6}$ A aplicação deste critério excluiu os seguintes museus: Museu da História, Imagem e Som (Campos do Jordão - SP); Museu Histórico, Documental, Fotográfico e do Som de Pará de Minas (Pará de Minas - MG); Museu da Imagem e Memória (Congonhas - MG); Museu do Som Regional (Porto Alegre - RS); Associação da Imagem e do Som de Porto Alegre (Porto Alegre - RS); e Museu do Som Independente (Curitiba - PR).

${ }^{7}$ Distinguimos o usuário em pesquisador e público em geral, por compreendermos que o pesquisador visa recuperar informações específicas a respeito de um tema/assunto e, que, quanto melhor essas forem tratadas e detalhadas contribuirá para suas investigações; Já por público geral, nos referimos a um grupo maior de usuários, de caráter heterogêneo, que devido a suas múltiplas características, possui necessidades informacionais variadas e que por isso se torna mais difícil atendê-las com precisão.

${ }^{8}$ Embora os termos Bibliografia e Referência Bibliográfica tenham seus conceitos muito precisos na área da Ciência da Informação, o fato de nomearem metadados de descrição de fotografia histórica deixa ambíguo o tipo de conteúdo que deve ser inserido nestes campos. 